\title{
A Proposal of Optical Wireless Communication with RF Subcarrier
} Hiroshi TAKANO and Shigeru SHIMAMOTO

Global Information and Telecommunication Institute, Waseda University 1-3-10, Nishi-Waseda, Shinjuku, Tokyo, 169-0051, Japan

E-mail: shima@sl.giti.wasedaac.jp

\section{Introduction}

The use of mobile phone influences the medical apparatus, and they discuss the use of mobile phone in the medical institution, in the train, ctc. Because a mobile phone radiates an electromagnetic wave that influences electric equipment. Optical wireless communication is safety for electric equipment, because it doesn $t$ produce any electromagnetic waves. Therefore we think it is suitable for wireless communication on these places, and we need to propose optical wireless access system for these places. And if we examine the characteristic of optical wireless communication, it is important to analyze diffuse link as well as LOS link. Analysis of characteristic by using Lambertian reflection surface in infrared wireless communication had been reported so far. But there are the reflection surfaces expext Lambertian model, for example glass or stainless.

In this paper, we propose the concept of optical wireless communication for thesc places, and we propose the models of reflection pattern for stainless or glass by numerical formula, and we examine the characteristic for the concept by numerical simulation due to this formula.

\section{Proposal scheme}

In this paper, we propose a concept of optical mobile communication as Fig.1. In this concept, we assume that RF signal from mobile phone is transformed into optical signal indoor with using present wireless access. So the optical wireless communication is used for uplink, and downlink is the same as usual mobile communication used an electromagnetic wave so far. And the oprical signal for uplink is modulated directly by RF signal. This scheme doesn $t$ ned the circuit to transform RF signal into base-band signal. We use two reflection surface models that we propose the one of them.

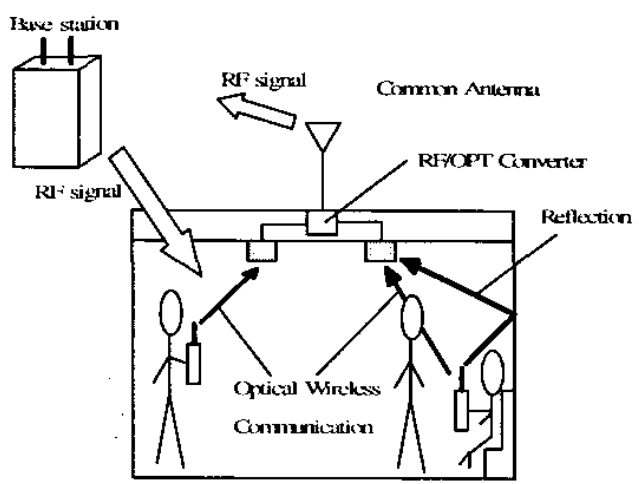

Fig. I The coneept of uptical wireless communication

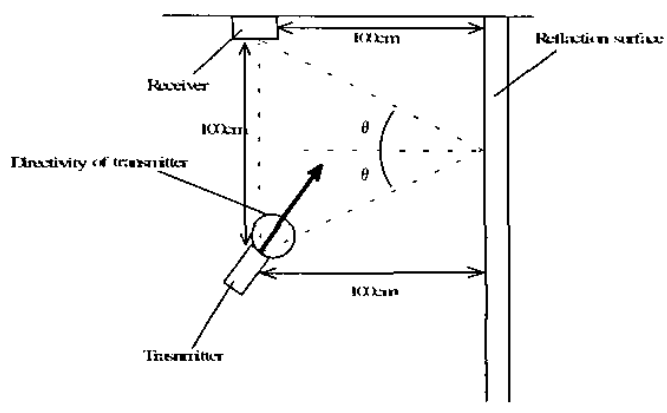

Fig.2 Simulation scheme for Oxical Signal mxtulated toy kn' sigral

III. The characteristic of RF signal sent by optical signal

We examine the characteristic of proposal scheme by numerical simulation. The arrangement for transmitter and receiver is shown by Fig.2, and QPSK signal is carried on RF signal. Fig.3 shows the proposal reflection model as stainless or glass, and Fig.4 shows Lambertan reflection model. The proposal reflection model is given by

$$
P_{r e f}=\rho(\theta) \frac{n(\theta)+1}{2 \pi} P_{s i g} \cos ^{n(\theta)}(\alpha-\theta)
$$

Here? is incidence, ? is the angle of radiation, $\mathrm{n}$ and? is the factor depending on ?. In numerical simulation, we assume that the shadowed LOS is formed such that the main signal path is obstructed in a part of communication time. And we examine a characteristic of proposal scheme with changing shadowing time ratio. 


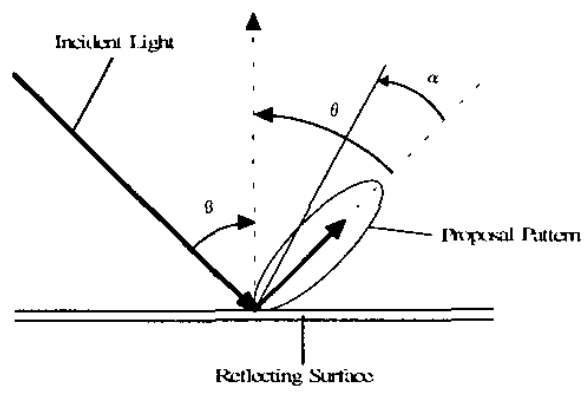

Fig.3 Pmposal nethetion pattern

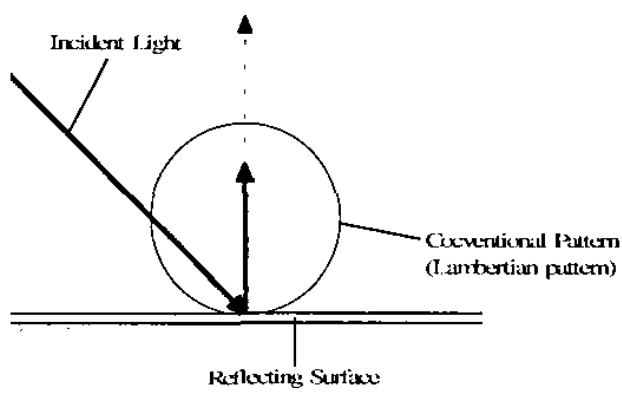

Fig.4 Conventional nelution pattern

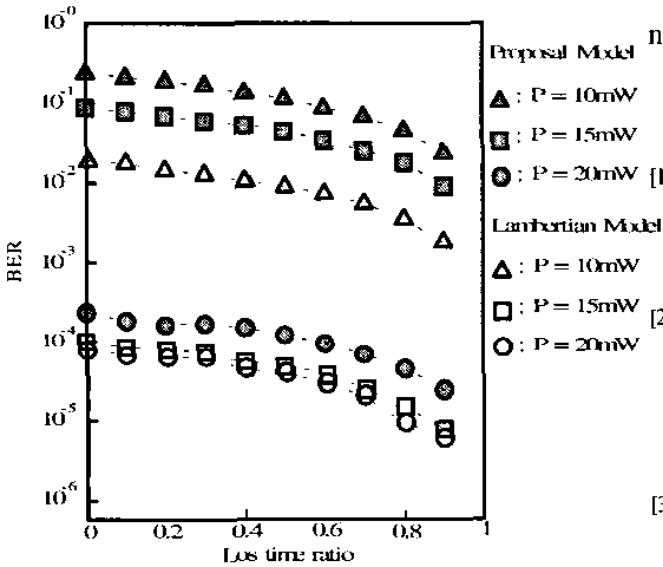

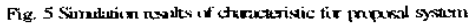

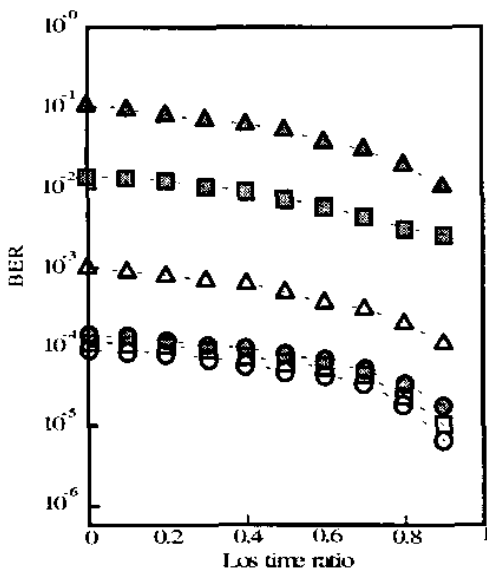

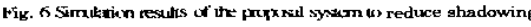
$\Delta: P=10 \mathrm{~mW}$ 口: $P=15 \mathrm{~mW}$ O: $P=20 \times m$
Fig. 5 shows simulation results. Fig.5 presents that BER condition in case of Lambertian reflextion surface is better than the proposal reflection surface.

IV. The proposal system to reduce shadowing

We consider the proposal system that the plural receivers are placed on the $c$ iling and plural received signals are added. In numerical simulation, we assume that the shadowed LOS is formed such that all LOS paths are obstructed in a part of communication time. Fig.6 shows the simulation results in case of two receivers. Fig.6 presents that $B E R$ condition is well or similar in case of proposal system to reduce shadowing.

\section{Conclusions}

We have proposed the concept of optical wireless communication for RF signal. We have proposed the models of reflection pattern by numerical formula and we examine the characteristic of the proposal concept and system to reduce shadowing by numerical simulation due to this formula.

\section{References}

] FRT R. GFELLER, URS BAPST, Wireless In-houke Data Communication via Diffuse infrard Ratiation Pros IEEE, vol.67, no.ll, pp.1474-1486, Nov.1979

Andrew P. Tang, Joseph M. Kahn, Keang-Po Ho, Wrekess lnftured Communication Links Using Multi-Beam Transmittux arxd Irraging Rewivers Proc. IEEE lnt. Conf. on Commun, pp. 180-186, Dalhs, TX, Jure.1979

[3] John R. Barry, Joseph M. Kahn, William J. Krause, Edwated A. Loe, David G. Messerschrnitt, Simulation of Multipath Impulse Response for Indoox Wireless Optical Chunels [EEE J. Seloct Areas Conmun., Vol.11, No.3, pp.367-379, April 1993 Imopoxal Mode[4] Joseph M. Kahn, John R. Barry, Malik D. Audeh, Jefrey B. A : $\mathbf{P}=1 \mathrm{OmW}$ Camuthers, William J. Krouse, Gene W. Marsh, Non-Dincted 国 : $P=15 \mathrm{~mW}$ Infrand Links for High-Capacily Wireless LANs IEEE Iersonal 0 : 1'= Xanw Commun, SccondQuarter, pp.12-25, 1994

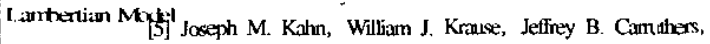
Experimental Characterization of Non-Dinacted Indoor Infrared Channels IEEE Trans. on Commun., Vol.43, No.2/3/4, pp.1613-1623, Feb/Mar/April.1994

[6] Roy You, Joseph M. Kilhn, Average Power Roduction Texhniques for Multiple-Subcamior Intensity-Modulated Optical Signaks IEFE Trans. on Commun, Vol.49, No.12, pp.2164.2171, Dax.200I

[7] Joxeph M. Kithn, John R. Barry, Wirtess Infrared Communications Proc IEEE, vol.85, no.2, pp.265-298, Feb.1997 